\title{
Morphological Changes of Ureteropelvic Junction (UPJ) in Case of Congenital Hydronephrosis - Review of Literature
}

\author{
Daila Pugacevska*,**, Valerija Groma***, Aigars Petersons*,**, Ivars Melderis****, Ainars Gilis** \\ ${ }^{*}$ Department of Pediatric Surgery, Riga Stradins University, Latvia \\ ${ }^{* *}$ Clinics of Pediatric Surgery, University Children's Hospital, Riga, Latvia \\ ***Institute of Anatomy and Anthropology, Riga Stradins University, Latvia \\ $* * * *$ Bureau of Pediatric Pathology, University Children's Hospital, Riga, Latvia
}

\begin{abstract}
Summary.
Congenital hydronephrosis is the most common cause of antenatally detected hydronephrotic transformation. Obstruction of UPJ can be intrinsic or extrinsic. Most cases of intrinsic stenosis do not require any treatment as it disappears during growth of a child. It is considered that in these cases wave of peristalsis appears again in aperistaltic UPJ. The cells responsible for peristalsis wave impulses, mechanisms of conduction of these impulses and regulation of them are not well recognized. Similarly, it is not clear why functional UPJ stenosis appears and disappears untreated in most cases. Researchers believe that all these processes are associated with the structural peculiarities of UPJ - changes in urothelium, muscle layer and innervation. The role of interstitial cells of Cajal (ICCS), important contributors of the urinary tract physiology, has not been extended to the obstruction of UPJ. Structural changes of UPJ wall are conclusive while choosing the most appropriate method of surgical treatment in newborns with congenital hydronephrosis.
\end{abstract}

Key words: Congenital hydronephrosis, UPJ obstruction, ureter peristalsis, Cajal cells.

\section{INTRODUCTION}

Congenital hydronephrosis or obstruction of UPJ is characterized by impaired urine flow from the renal pelvis to proximal ureter, followed by dilatation of collection system and potential damage to renal parenchyma. This is the most common cause of antenatal hydronephrosis $(6,12)$. Hydronephrotic transformation is diagnosed in one of hundred prenatal USG (19), and obstruction of UPJ is the most common cause of clinically important antenatal hydronephrosis, seen in one of 500-1000 live births. Therefore congenital hydronephrosis is the most common congenital anomaly of genitourinary tract, pediatric urologists have to deal with (6). The most difficult step in management of congenital hydronephrosis is to differentiate obstructive condition from non-obstructive. Obstruction is considered to be not only mechanical obstacle to the flow of urine, but also a functional problem $(6,12)$. Intrinsic stenosis is found in $67 \%$ of all cases, some of them only functional. It is believed that children suffering from functional UPJ stenosis do not need surgical treatment as the disease can disappear spontaneously during the first year in $80 \%$ cases (46). Open pyeloplasty by Anderson-Hynes is still considered to be the golden standard of surgical treatment, which is based on excision of stenosed UPJ, creating anastomosis between renal pelvis and ureter. As technologies develop, alternative mini-invasive methods like endopyelotomy, balloon dilatation and Acucise approach have been proposed for treatment. Endourologic treatment is based on endoluminal balloon dilatation and/or wall incision thus expanding the diameter of ureter lumen (14). The effectiveness of these methods is variable and mostly based on clinical data of adult population $(14,33)$. Some authors mention the use of these methods in children over 2 years of age. In PubMed 10 year review, only 2 publications (2009 and 2011) can be found on the use of balloon dilatation and endopyelotomy in treatment of UPJ obstruction in newborns $(5,36)$. These publications originate from Madrid and has small amount of patients - 16 newborns underwent balloon dilatation in 2009 (5), and 5 patients had cold-knife retrograde endoscopic endopyelotomy in 2011 (36). The use of endourologic technologies in treatment of congenital hydronephrosis is limited by such causes of the pathology as high insertion of the ureter in renal pelvis, aberrant blood vessel for lower pole of the kidney and significant dilatation of renal pelvis (14). We consider changes in UPJ wall structure causing aperistalsis of ureter to be the most important limiting factor. Still mechanisms of ureter peristalsis and pathological processes of UPJ in congenital hydronephrosis patients remain unclear.

\section{Peristalsis of Ureter}

Transportation of urine from kidney to bladder is an active process, based on the well-coordinated one-way peristalsis (17). It is believed that contraction creating peristaltic waves in the ureter is initiated by cells with pacemakeractivityin the proximal part of renal calices (17, $25,27,35)$. Both - origin and conduction mechanisms of peristalsis wave are not completely known. Despite the 
fact, that wall of ureter is well innervated, many authors consider myocytes to play the main role in peristalsis processes $(11,17,35,41,44)$. Tahara et al. proved that conduction of nerve impulse happens myogenically from one cell to another (44). Seki et al. discovered that activity of smooth muscles of rabbit renal calices is resistant to acetylcholine, norepinephrine and neuronal blockers, thus proving it has truly myogenic origin (41). Moreover, it is proved that peristalsis persists in isolated and denervated PUS, identical to that in vivo, and it cannot be blocked by neuronal blockers $(11,40)$. Some authors discovered that contractions of ureter can be influenced by sympathic and parasympathic blockers in vivo, sensoneural blockers and prostaglandine inhibitors in vitro $(18,24)$. Effective peristalsis recovers shortly after ureteral end-to-end anastomosis surgery, yet one knows that reinnervation takes much more time (4, $11,40)$ allowing consider that motility of the ureter is mainly myogenic process, while innervation plays the regulating role $(11,17,40)$. Defective smooth muscle cells in the wall of ureter lead to impaired conduction of electrical impulses and aperistaltic zone that clinically manifests as obstruction of urinary tract (17). It is considered that most cases of congenital hydronephrosis are due to intrinsic or functional obstruction, caused by morphological changes of UPJ (38).

Normal anatomy and physiology. Anatomy and histology of the ureter is not constant along its length. The wall of PUS consists of 3 layers - mucosa, muscularis and adventitia. Mucosal transitory epithelium can adjust to tension. Superficial cells protect the ureter wall from urine exposure. Lamina propria, consisting of loose connective tissue and housing vessels and nerve fibers, connects mucosa with muscle layer. The latter is thin and consists of muscle cells, interspersed by connective tissue. The inner muscle layer is circular, outer - longitudinal. Using video microscopy, Osman et al. specified function of circular muscular layer as conduction of urine boluses distally, whereas, longitudinal contractions downwards as producers of passive axial tension within the upper part of the ureter, making "ureter diastole" that promotes refilling of ureter and formation of next urine bolus (34). The frequency and amplitude of ureter contractions depend on urine volume. During low urine flow very few contractions were detected, while increasing diuresis cause one contraction after another. It is considered that pacemaker cells react to the increasing urine volume and pressure in renal pelvis thus generating more and more action potentials $(8,9,35)$. It is not known which cells are responsible for generation of these potentials. The role of interstitial cells of Cajal (ICCs) in normal physiological processes of urinary tract remains unclear. ICCs as pacemakers have been found in the gastrointestinal tract, bladder, prostate and UPJ of many mammals $(16,25,26,31)$. The role of ICCs has been proved in pathogenesis of such dysmotility-induced diseases as hypertrophic pylorostenosis, Hirschprung's disease, intestinal pseudoobstruction syndrome and constipation. Perhaps, like in gastrointestinal tract ICCs play a significant role in conduction, regulation and modulation of peristalsis in the urinary tract (43). Some authors suggest that they play a role of pacemakers, working together with smooth muscle cells in the conduction of impulses $(26,43)$. ICCs are sandwiched between nerve terminal and myocytes assisting in impulse conduction (39). According to Santicoli et al. pacemaker function can be performed by specialized smooth muscle cells (SMCs) (40), whereas, Lang et al. insisted on necessity of close cooperation of both cells ICCs and SMCs in the generation and conduction of peristalsis wave (28).

\section{Morphological changes of stenosed UPJ.}

Current research shows that histological changes in congenital hydronephrosis can be found in UPJ mucosa and muscularis $(7,10,13,20,21,22,30,32,42)$. Greatly varying nerve fibers and ICCs were discovered in these patients $(2,15,21,22,23,29,30,32,43,47)$.

The role of the urothelium in the development of congenital hydronephrosis is poorly understood (7). Experimental models reveal hyperplasia of transitional epithelium $(1,3,7)$. In human tissue, mononuclear cells and eosinophilic leukocytes can be seen in a zone of stenosis. $60 \%$ of samples showed a six-layered epithelium with degenerative changes of cells along with vacuolization and pyknotic changes of nuclei. Chiou et al. hypothesized that the cause of infiltration could be allergic inflammation, and, perhaps, UPJ obstruction has heterogeneous causes (7).

Analysis of UPJ muscle layer in patients with obstruction revealed that muscle cells tend to be thinner and fewer compared to those of healthy subjects $(21,22,32)$. According to these publications, intercellular spaces between muscle cells are becoming six to seven times wider than that of normal tissue, whereas, Murakamo et al. reported on collagen fibers organized in firm compact structures, when compared to healthy subjects, where collagen lies in loose undulate bundles. Pericellular collagen fibrils surrounding myocytes were interwoven to form a dense felt-like structure against thin lacelike sheaths in controls (32). Some authors consider that along with structural changes, functionality of myocytes is also impaired $(10,20,30)$. Kajbafzadeh et al. discovered increased SMCs apoptotic index in stenosed tissue constituents in congenital hydronephrosis. Positive correlation between SMCs apoptosis and amount of collagen/elastin can be seen reflecting elevation of connective tissue proportion in the wall of the ureter as compared to muscle counterpart (21). Some authors propose detection of collagen-smooth muscle ratio, which together with amount of elastin in the sample can predict reconvalescence length after pyeloplasty. Patients with lower collagen-muscle ratio and less elastin in UPJ have a shorter reconvalescence period after surgery (13). Not only quantity, but also quality of myocytes appears to be an important factor (32). Changes of myocyte cytoskeleton leading to a significant loss of function and increased cell death were demonstrated by Magno et al. (30).

There are data on diminution of innervation by one 
third in stenosed tissue (32). In pathologically impaired tissue nerve fibers can be found in the adventitia and submucosa, but these are lacking in the muscle layer. By contrast, the normal tissue reveals plentiful nerve of fibers in the submucosa, adventitia, and a lesser amount in the muscle layer (22).

ICCs have been studied widely, focusing on the potential role of these cells in pathogenesis of congenital hydronephrosis. It is discovered that human UPJ contains Cajal cells identical to those found in the gastrointestinal tract. These are spindle-shaped cells with narrow cytoplasm, large nucleus and two cytoplasmic processes $(23,43)$. Localization of ICCs is mostly restricted to the muscle layer, and, specifically, to the entire contour of the circular muscle layer $(15,23,43)$. The patients with congenital hydronephrosis demonstrate very few if any of ICCs $(15,43,47)$, although reports published on this matter are very controversial $(2,23)$. According to Apoznanski et al., a number of ICCs was not statistically different analyzing graded age groups of pediatric UPJ (2), whereas, Koleda et al. study showed that a number of Cajal cells in hydronephrotic samples is higher than that of healthy subjects. In addition, these authors found decrease in Cajal cells along with aging, whereas, the increase is explained by an initial compensatory mechanism that ceases by time (23).

\section{CONCLUSIONS}

Description of histopathology pattern in case of congenital hydronephrosis available in the literature is not unambiguous. The contribution of the urothelium changes to the pathogenesis of congenital hydronephrosis remains unclear. The most common structural changes revealed in PUS include atrophy and dysfunction of myocytes, increased accumulation of extracellular matrix accompanied by interstitial collagen deposition, and diminution of innervation. Each of these changes can significantly affect motility of PUS leading to urine transportation problems. A role of ICCs in the formation and regulation of ureter peristalsis still remains unclear. Taking into account the significant changes in UPJ wall of congenital hydronephrosis patients, use of miniinvasive endourologic treatment methods in newborn is dubious. Excision of UPJ segment during open pyeloplasty removes the pathogenetic cause of the disease and therefore is considered to be the method of choice.

\section{Conflict of interest: None}

\section{Acknowledgement}

A study by The National Resarch programme project no. 8 "Clinical, molecular-biological, and biomechanical research of morphofunctional list and treatment of Congenital and acquired diseases of Childhood."

\section{REFERENCES}

1. Abbott BD, Birnbaum LS, Pratt RM. TCDD-induced hyperplasia of the ureteral epithelium producēs hydronephrosis in murine fetuses // Teratology, 1987: 35:329 - 334
2. Apoznanski W, Koleda P, Wozniak Z, et al. The distribution of interstitial cells if Cajal in congenital ureteropelvic junction obstruction // Int Urol Hephrol, 2013; 45(30):607 - 12

3. Baumgart $\mathrm{P}$, Muller KM, Lison AE. Epithelial abnormalities in the renal pelvis in experimental hydronephrosis and pyelonephritis // Pathol Res Pract, 1983; 176:185 - 195

4. Caine M, Hermann G. The return of peristalsis in the anastomosed ureter: A cine-radiographic study // Br J Urol, 1970; 42;164

5. Carrera N, Parente A, Rivas S, Romero R, Angulo JM. Cold-knife retrograde endoscopic endopyelotomy (Cutting-Balloon) in children with ureteropelvic junction obstruction: early results // Cir Pediatr. 2011; 24(4): 192 - 5

6. Chertin B. Pelvi-ureteric junction obstruction // In: Puri P, Hollwarth M. Pediatric surgery: Diagnosis and management. Heidelberg: Springer-Verlag; 2009; $839-842$

7. Chiou YY, Shien CC, Cheng HL, et al. Intrinsisc expression of Th2 cytokines in urothelium of congenital ureteropelvic junction obstruction // Kidney Int, 2005; 67:638 - 646

8. Constantinou CE, Granato JJ, Govan DE. Dynamics of upper urinary tract: V-Accommodation in the rate and stroke volumes of ureteral peristalsis as a responses to transient alteration in urine flow rate // Invest Urol, 1979; 29:249 - 264

9. Constantinou CE, Hrynczuk JR. Urodinamics of upper urinary tract // Invest Urol, 1976; 14:233 240

10. Cutroneo G, Arena S, Anastasi G, et al. Altered cytoskeletal structure of smooth muscle cells in ureteropelvic junction obstruction // J Urol, 2011; 185(6):2314 - 9

11. DiBona GF, Kopp UC. Neural control of renal function // Physiol Rev, 1997; 77:75 - 197

12. Dilatation of the upper urinary tract (ureteropelvic junction and ureterovesical junction obstruction) // Paediatric urology guidelines, 2012;58-61

13. Dong SK, Ji YJ, Hyeon JJ, et al. Elastin content of the renal pelvis and ureter determines postpyeloplasty recovery // J Urol, 2005; 173:962 - 966

14. Eden, G.H.: Minimally invasive treatment of ureteropelvic junction obstruction: a critical analysis of results. Eur. Urology, 2007; 52: 983-989

15. Eken A, Erdogan S, Kuyucu Y, et al. Immunohistochemical and electron microscopic examination of Cajal cells in ureteropelvic junction obstruction // Can Urol Assoc J, 2012, 10:1 - 6

16. Exintaris B, Klemm MF, Lang RG. Spontaneus slow wave and contractile activity of the guinea pig prostate // J Urol, 2002; 168:315

17. Feng C. Genetic and developmental basis for urinary tract obstruction // Pediatr Nephrol, 2009; 24:1621 - 1632

18. Golenhofen K, Hannappel J. Normal spontaneus activityof the pueloureteral system in the guineapig // Pflugers Arch, 1973; 341:257 - 270 
19. Gould SW, Figueroa TE, Robinson BW, Reichard $\mathrm{KW}$, Recent advances in the prenatal diagnosis and subsequent managenent of congenital anomalies // The Journal of Lancaster General Hospital, 2011; 6(1): $5-9$

20. Hosgor M, Karaca I, Ulukus C, et al. Structural changes of smooth muscle in congenital ureteropelvic junction obstruction // J Pediatr Surg, 2005; 40(10): $1632-6$

21. Kajbafzadeh AM, Payabvash S, Salmasi AH, et al. Smooth muscle cell apoptosis and neural development in congenital ureteropelvic junction obstruction // J Urol,2007; 176(2):718 - 23

22. Kaya C, Bogaert G, de Ridder D, et al. Extracellular matrix degradation and reduced neural density in children with instrinsic ureteropelvic junction obstruction // J Urol, 2010; 76(1):185 - 9

23. Koleda P, Apoznanski W, Wozniak Z, et al. Changes in interstitial cell of Cajal-like cells density in congenital ureteropelvic junction obstruction // Int Urol Nephrol, 2012; 44(1):7 - 12

24. Lang RG, Davidson ME, Exintaris B. Pyeloureteral motility and ureteral peristalsis: esential role of sensory nerves and endogenus prostaglandīns // Exp Physiol, 2002; 87:129 - 146

25. Lang RJ, Exintaris B, Teele ME, et al. Electrical basis of peristalsis in the mammalian upper urinary tract // Clin Exp Pharmacol Physiol, 1998; 25:310 - 321

26. Lang RJ, Klemm MF. Interstitial cell of Cajal-like cells in the upper urinary tract // J Cell Mol Med, 2005; 9:543 - 556

27. Lang RJ, Takano $\mathrm{H}$, Davidson $\mathrm{ME}$, et al. Characterization of the spontaneus electrical and contractile activity of smooth muscle cells in the rat upper tract // J Urol,2001; 166:329 - 334

28. Lang RJ, Tonta MA, Zoltkowski BZ, et al. Pyeloureteric peristalsis: role of atypical smooth muscle cells and intersticial cells of Cajal-like cells as pacemarkers // J Physiol, 2006; 576:695 - 705

29. Lang RJ, Zoltkowski BZ, Hammer JM, et al. Electrical characterization of interstitial cells of Cajal-like cells and smooth muscle cells isolated from the mouse ureteropelvic junction // J Urol, 2007; 177(4): $1573-80$

30. Magno C, Arena S, Speciale F, et al. Integrin expression of smooth muscle cells in ureteropelvic junction obstruction // Ital J of Anat and Embryol, 2010; 115, nl/2 (Supplement)

31. McCloskey KD, Gurney AM. Kit positive cells in the guinea pig bladder // J Urol, 2002; 168:832

32. Murakamo M, Nonomura K, Yamashita T, et al. Structural changes of collagen components and diminuation of nerves in congenital ureteropelvic junction obstruction // J Urol, 1997; 157(5):1963 - 8

33. Nadu A, Mottrie A, Geavlete P. Ureteropelvic junction obstruction: Which surgical approach? // European Urology Supplements, 2009; 8: 778 - 781

34. Osman F, George L, et al. A novel videomicroscopic technique for studying rat ureteral peristalsis in vivo // World J Urol, 2008; 27(2):265 - 70
35. Osman F, Romics O, Nyrady P, et al. Ureteral motility // Acta Phys Hung, 2009; 96(4):407 - 426

36. Parente A, Angulo JM, Rivas S, Romero RM, Corona C, Tardaguila A. Percutaneous endopyelotomy with electrocautery: modified techniques in the treatment of ureteropelvic junction obstruction in a child under 2 years // Arch Esp Urol, 2012; 65(9): $837-40$

37. Parente Hernández A, Angulo Madero JM, Romero Ruiz RM, Rivas Vila S, Laín Fernández A, Fanjul Gómez M. Medium-term results of the endourological management with balloon dilatation of the ureteropelvic junction stenosis in infants // Actas Urol Esp, 2009;33(4):422-8

38. Rosen S, Peters CA, Chevalier RL, et al. The kidney in congenital ureteropelvic junction obstruction: a spectrum from normal to nephrectomy // J Urol, 2008; 179:1257 - 63

39. Sanders KM. A case of interstitial cells of Cajal as pacemakers and mediators of neurotransmission in the gastrointestinal tract // Gastroenerology, 1996; 111: 492

40. Santicoli P, Maggi CA. Myogenic and neurogenic factors in the control of pyeloureteral motility and ureteral peristalsis // Pharmacol Rev, 1998; 50:683 721

41. Seki N, Suzuki H. Electrical properties of smooth muscle cell membrane in renal pelvis of rabbits // Am J Phys, 1990; 259:F888 - F894

42. Sokolis DP. Identification and characterisation of regional variation in the material properties of ureter according to microstructure // Comput Methods Biomech Biomed Engin, 2013; 25

43. Solari V, Piotrowska P, Puri P. Altered expression of interstitial cells of Cajal in congenital ureteropelvic junction obstruction // J Urol. 2003; 170:2420 $-2422$

44. Tahara H. The three dimensional structure of the musculature and the nerve elements in the rabbit ureter // J Anat, 1990; 170:183 - 191

45. Wilkinson AG, Rajan P, MacKinlay GA. Endoluminal balloon dilatation for pelvi-ureteric junction obstruction in children: an effective alternative to open pyeloplasty // J Pediatr Urol, 2005; 1 (4): 301 - 5 46. Woodward M, Frank D. Postnatal management of antenatal hydronephrosis // BJU Int, 2002; 89:149 - 156

47. Yang X, Zhang Y, Hu J. The expression of Cajal cells at the obstruction site of congenital pelviureteric junction obstruction and quantitative image analysis // J Pediatr Surg, 2009; 44(12):2339 - 42

\section{Address:}

Daila Pugacevska

Department of Pediatric Surgery

Children`s University Hospital

Vienibas gatve 45

LV - 1004, Riga, Latvia

E-mail: Daila.Pugacevska@rsu.lv 